\title{
Feasibility and safety of using a novel traction wire for endoscopic submucosal dissection of challenging gastrointestinal neoplasia
}

Endoscopic submucosal dissection (ESD) is an en bloc resection technique for gastrointestinal neoplasia but is associated with high risk of complications [1]. The ProdiGl traction wire (Medtronic, Minneapolis, Minnesota, USA) is a novel device for improving the safety of ESD.

The technique involves the creation of a circumferential mucosal incision and a mucosal flap, which is then grasped by the traction clip with the wire. A second clip is then used to grasp the traction wire and attach it to the mucosa on the opposite wall. As the lesion base is resected the traction wire is designed to curl and maintain tension. The amount of traction can be further increased or decreased by inflation or deflation of the lumen. Our video aims to show two cases where ESD would be very challenging without the traction wire ( $\vee$ Video 1 ).

The first case is of a 40 -mm granular laterally spreading tumor growing into the appendix. Conventional ESD was commenced to create a circumferential mucosal incision followed by creation of a large mucosal flap on the anal side of the lesion. Further dissection was hampered owing to the lesion going into the appendicular lumen. At this point, the traction device was deployed as described above to expose the submucosa going into the lumen for safe dissection of the lesion (> Fig. 1).

The second case shown is of an early gastric cancer at the pyloric rim extending into the duodenum. Circumferential mucosal incision was followed by submucosal dissection. The dissection was stopped short of the pyloric rim to prevent migration of the lesion into the duodenal bulb making subsequent dissection challenging. The traction device was deployed as described above. This exposed the submucosal space and prevented migration of the lesion into the duodenum by pulling it into the stomach as the dissection progressed ( $\triangleright$ Fig. 2 ).

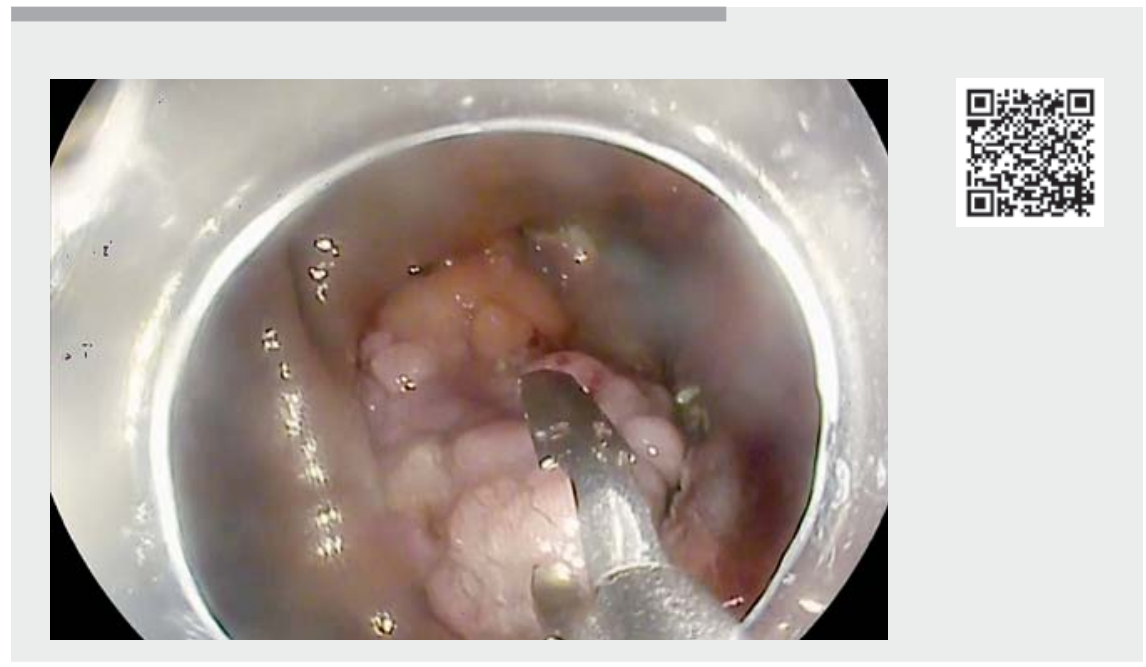

$\nabla$ Video 1 Cases demonstrating the use of the ProdiGl traction wire during endoscopic submucosal dissection. Case 1 shows dissection of a nodular laterally spreading lesion involving the appendicular opening. Case 2 demonstrates dissection of an early gastric cancer straddling the pyloric rim. Both cases demonstrate how the traction facilitates opening up the submucosal plane and aids visualization during dissection.

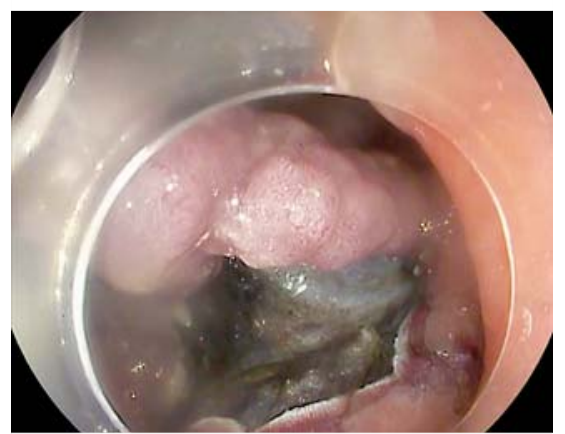

- Fig. 1 Traction of a granular laterally spreading lesion at the appendiceal orifice, facilitating visualization of the submucosal planes during endoscopic submucosal dissection.

These cases prove the added value of this traction device.

Endoscopy_UCTN_Code_TTT_1AQ_2AJ

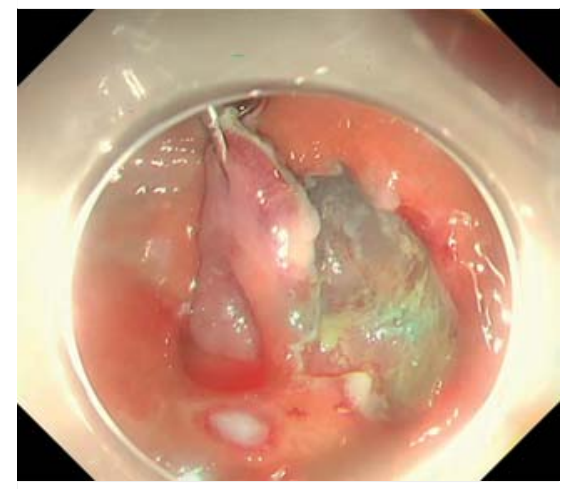

Fig. 2 Traction of an early gastric cancer at the pyloric rim, exposing the submucosal space and tethering the lesion to the gastric wall to prevent prolapse of the lesion into the duodenum during submucosal dissection.

\section{Competing interests}

P. Bhandari: research grants or advisory board for: Fujifilm, Boston, Olympus, Pentax, 3-D matrix, NEC(Japan) and Medtronics. 


\section{Shahila Perveen Aslam, Mohamed}

Abdelrahim, Sharmila Subramaniam, Pradeep

\section{Bhandari}

Gastroenterology Unit, Queen Alexandra Hospital, Portsmouth Hospitals NHS Trust, Portsmouth, United Kingdom

Corresponding author

\section{Pradeep Bhandari, MD}

Gastroenterology Unit, Queen Alexandra Hospital, Southwick Hill Road, Cosham, Portsmouth, Hampshire, PO6 3LY,

United Kingdom

Pradeep.bhandari@porthosp.nhs.uk
[1] Farhat S, Chaussade S, Ponchon T et al. Endoscopic submucosal dissection in a European setting: a multi-institutional report of a technique in development. Endoscopy 2011; 43: 664

\section{Bibliography}

Endoscopy 2022; 54: E606-E607

DOI 10.1055/a-1707-1390

ISSN 0013-726X

published online 26.1.2022

(c) 2022. Thieme. All rights reserved.

Georg Thieme Verlag KG, Rüdigerstraße 14, 70469 Stuttgart, Germany

\section{ENDOSCOPY E-VIDEOS}

https:/|eref.thieme.de/e-videos

口回 Endoscopy E-Videos is an

open access online section, 靣舴: reporting on interesting cases and new techniques in gastroenterological endoscopy. All papers include a high quality video and all contributions are freely accessible online. Processing charges apply (currently EUR 375), discounts and wavers acc. to HINARI are available.

This section has its own submission website at

https://mc.manuscriptcentral.com/e-videos 